
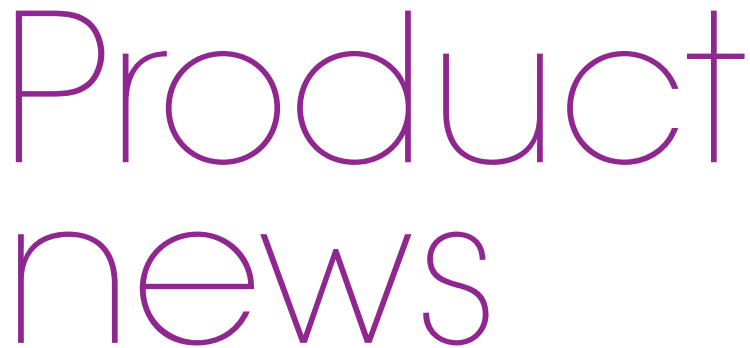

Product news is provided as a service to readers using text and images from

the manufacturer, supplier or distributor and does not imply endorsement

by BDJ Team. Normal and prudent research should be exercised before

purchase or use of any product mentioned.

\section{WIN A DESIGNER TONGUE CLEANSER}

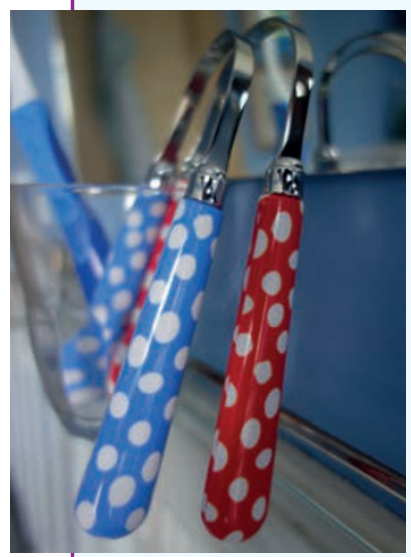

The Italian made AMANO tongue cleanser is designed to add elegance to the 2,000-yearold ritual of tongue scraping. Tongue cleansing was particularly in vogue in the eighteenth and nineteenth

centuries, with George Washington and Victorian aristocracy firm advocates of the routine.

Simple to use and with a range of eyecatching designs, the nickel and alloy head of the AMANO tongue cleanser is gently drawn down the tongue's surface, removing all debris in two to three strokes. Due to its precise design and weight, patients will not gag with an AMANO.

AMANO has three of its latest tongue cleansers to give away to $B D J$ Team readers. To be in with a chance of winning one, just answer the following question:

Q. Which American President is known to have used a tongue scraper (it can still be viewed in his museum)?
A. George Washington
B. Bill Clinton
C. Abraham Lincoln

The first three people to email the correct answer, A, B or C, to mano@ amanotonguecleanser.com, by 3 February 2017, will win an AMANO tongue cleanser. www.amanotonguecleanser.com AMANO is available in Selfridges, Harrods and Planet Organic

\section{MAKE A POINT} OF CONTACT

Patient Connections from innovative dental software developers, Welltime, gives you the opportunity to communicate with your patients like never before.

An easy-to-use system that integrates seamlessly with your current digital facilities, Patient Connections allows you to send your patients comment forms and questionnaires after each appointment. The information you receive from these provides essential feedback with which you can improve your service.

Patient Connections also enables you to review and monitor this feedback in a simple manner - and then make use of it on your website. You will also be able to send patients pertinent articles and oral health tips through the programme, to offer them an even better service.

What's more, this eclectic programme allows you to send patients bespoke clinical advice and education, to support the advice you have given them in the surgery. This promotes better patient understanding and gives your patients the knowledge they need to take their own dental care into their hands.

To find out more about what Patient Connections could do for your practice and your patients, contact the expert team at Welltime today on 07999991 337, email sales@welltime.co.uk or visit www. welltime.co.uk.

\section{RAISING AWARENESS OF TOOTH WEAR AND DENTINE HYPERSENSITIVITY}

GSK is leading a campaign to raise awareness among dentists, DCPs and patients about two common conditions: erosive tooth wear and dentine

hypersensitivity (DH).

Seventy-seven percent of British adults exhibit signs of tooth wear. ${ }^{1}$ You can now download the GSK BEWE app from the App Store for a comprehensive guide to erosive tooth wear diagnosis. Recommend Pronamel for daily protection from the effects of erosive tooth wear.

Dentine hypersensitivity is also widespread. $41.9 \%$ of adults have experienced it $^{2}$ and over $70 \%$ of sufferers consider the sensations to take pleasure out of eating and drinking. ${ }^{3}$ Recommend

Sensodyne Repair \& Protect for daily repair from $\mathrm{DH}$.

For more information on these conditions and other CPD materials, visit: https://www.gsk-

1. Disease and related disorders - a report from the Adult Dental Health Survey 2009. social care, 2011 dentalprofessionals.co.uk/.
Erosive tooth wear Enamel Dentine Hypersensitivity Dentine
The Information Centre for health and

2. Addy M. Int Dent J 2002; 52: 367-375.

3. GSK Data on File RH02026. 